\title{
Türkiye Üniversitelerinde Dramatik Yazarlık Eğitimi: Nitel Bir Durum Çalışması $^{1}$
}

\section{Dramatic Writing Education in Turkish Universities: A Qualitative Case Study}

\author{
Ezgi Deniz ALPAN , Arş. Gör. Dr., Atatürk Üniversitesi, ezgidenizalpan@gmail.com \\ Özlem BELKIS , Doç. Dr., Dokuz Eylül Üniversitesi, ozlem.belkis@deu.edu.tr \\ Hatice ŞAŞMAZ , Arş. Gör., Düzce Üniversitesi, gmhaticeyilmaz@gmail.com \\ Yunus Emre GÜMÜŞ ，Arş. Gör., Dokuz Eylül Üniversitesi, yegumus@gmail.com
}

Yasemin Sevim SALMAN ${ }^{\text {ID }}$, Dr. Öğr. Üyesi, Dokuz Eylül Üniversitesi, yasemin.sevim@deu.edu.tr

\begin{abstract}
Alpan, E. D., Belkıs, Ö., Şaşmaz, H., Gümüş, Y. E. ve Salman, Y. S. (2021). Türkiye Üniversitelerinde Dramatik Yazarlık Eğitimi: Nitel Bir Durum Çalışması. Batı Anadolu Eğitim Bilimleri Dergisi, 12 (2), 357-373.

Geliş tarihi: 30.05 .2021

Kabul tarihi: 06.07.2021

Yayımlanma tarihi: 28.12 .2021
\end{abstract}

Öz. Dramatik yazarlık, sahne sanatları eğitiminin oyunculuk ve sahne tasarımı ile birlikte temel taşlarından biridir. Günümüzde bu eğitim, tiyatro estetiğinin değişim ve dönüşümüne paralel olarak sürdürülmektedir. Türkiye'de 1964'te başlayan lisans düzeyindeki tiyatro eğitiminin içinde dramatik yazarlık alanı da bulunmakta, bugün de lisans düzeyinde Ankara Üniversitesi, Atatürk Üniversitesi, Dokuz Eylül Üniversitesi, İstanbul Üniversitesi, Kocaeli Üniversitesi, Süleyman Demirel Üniversitesi, Uludağ Üniversitesi ve Yüzüncü Yıl Üniversitesi olmak üzere sekiz üniversitede sürdürülmektedir. Eğitimin iyileştirilme ve güncellenmeye ihtiyaç duyan doğası, bir tartışma zemini oluşturulması için var olan koşulların bilinmesini zorunlu kılar. Desteğe ihtiyaç duyulan ya da güçlü alanların keşfedilmesi bu anlamda önemlidir. Bu çalışma Türkiye'deki Dramatik Yazarlık Eğitiminin halihazırdaki koşullarını incelemek ve temel demografiyi oluşturmak, muhtemel bir tartışmaya zemin sunmak amacını taşımaktadır. Araştırmada nitel araştırma yöntemi, durum çalışması deseninde kullanılmışır. Araştırmaya Dramatik Yazarlık Eğitimini aktif olarak sürdüren yedi üniversite katılmıştır. Derinlemesine yarı yapılandırılmış görüşmeler ile toplanan veriler hazırlık, çözümleme ve kodlama olmak üzere üç aşamada çözümlenmiştir. Bulgular araştırma soruları bağlamında birimlerin kuruluşları ile kadro, kontenjan, mekân yeterlilikleri bağlamında örneklenerek sunulmuştur. Araştırmanın sonuçları, Dramatik Yazarlık Eğitiminde ders mekanlarının sayısal ve işlevsel olarak ihtiyacı karşılamadığını, ilgili birimlere tahsis edilmiş kadroların yetersiz olduğunu, öğrenci kontenjanlarının az ya fazla olmasının eğitimi doğrudan etkilediğini göstermiştir. Ayrıca birimlerin, staj ve pratik çalışma faaliyetlerini öğrencilerin kariyer gelişimleri açısından başat bir öge olarak gördükleri de anlaşılmaktadır.

Anahtar Kelimeler: Dramatik yazarlık, Dramatik yazarlık eğitimi, Sahne sanatları, Oyun yazarlığı, Yaratııı yazarlık

\footnotetext{
${ }^{1}$ Bu makale, Dokuz Eylül Üniversitesi Buca Eğitim Fakültesi tarafından 28-29 Mayıs 2021 tarihlerinde düzenlenen UBEST - 2. Uluslararası Bilim, Eğitim, Sanat ve Teknoloji Sempozyumu'nda sözlü bildiri olarak sunulmuştur.
} 
Abstract. Dramatic writing is one of the foundations of performing arts education, along with acting and stage design. Today, this education continues with the change and transformation of theater aesthetics. Dramatic writing department is also included in the undergraduate theater education that started in 1964 in Turkey. Today, this education is carried out at the undergraduate level in eight universities: Ankara University, Ataturk University, Dokuz Eylul University, Istanbul University, Kocaeli University, Suleyman Demirel University, Uludag University and Yuzuncu Yil University. The nature of education, which needs improvement and updating, necessitates knowing the existing conditions in order to create a discussion. It is important to discover areas of strength or need for support. This study aims to examine the current conditions of dramatic writing education in Turkey, to establish the basic demographics and to provide a basis for a possible discussion. In the research, the qualitative research method was used in the case study design. Seven universities actively pursuing dramatic writing education participated in the study. The data collected through in-depth semi-structured interviews were analyzed in three stages as preparation, analysis and coding. Results; within the scope of the research questions, the organizations of the units and the academic staff, quota, and class qualifications were presented with examples. The results of the research showed that the classrooms for dramatic writing education do not supply needs numerically and functionally, the academic staff allocated to the relevant departments are insufficient, and the less or more student quotas directly affect the education.

Keywords: Dramatic writing, Dramatic writing education, Performing arts, Playwriting, Creative writing. 


\section{Extended Abstract}

Introduction. In Turkey, the first playwriting courses began to be given at Ankara University in 1964 and Ege University in 1976. Today, dramatic writing education continues in eight different universities. Dramatic writing education in our country has a lag of almost half a century when compared to the examples in the world. However, the process that has passed since the beginning of education is an effective period for some of its components to wear out and lose their function in the face of developing technology and transforming social conditions. The limited research in this area also indicates the need for renewal in dramatic writing education programs within the framework of the requirements of contemporary education. The nature of education that needs improvement and updating necessitates knowledge of the existing conditions in order to establish a discussion base. This study aims to examine the current conditions of dramatic writing education in Turkey and to establish the basic demographics and thus to lay the groundwork for a possible discussion. In the research, a due diligence was made by determining the institutional opportunities and needs of dramatic writing education at the undergraduate level. In this context, the basic research question is: "What are the institutional opportunities and needs of the academic departments that provide dramatic writing education in Turkey?". The sub-questions of the research were planned as follows:

- When and by whom were the departments established?

- What is the current academic staff and staff structure of the departments?

- What are the classroom facilities of the departments?

- What are the departments strategies for preparing and monitoring the curriculum?

- What are the views and approaches of the departments regarding the number of quotas?

- What are the career development supports offered to students?

- How are relations with alumni maintained?

- What are the institutional needs of dramatic writing education?

Method. In this research, the qualitative research method was used in the case study design. The 2019 fall semester education conditions of academic departments that provide undergraduate dramatic writing education in Turkey were determined as the situation, and Creswell's (2013) research procedure was adopted. Seven academic departments that provide dramatic writing education at the undergraduate level in Turkey participated in the research. The data were collected through structured in-depth interviews consisting of nine questions with the heads of departments or heads of branches of the academic units that make up the study group. Total interview time lasted 380 minutes. These interviews were recorded with the permission of the participants, deciphered by the researchers who conducted the interview, and prepared for analysis. The collected data were analyzed in the context of the research questions with a horizontal understanding by two researchers with collaborative coding.

Results. Classrooms were found insufficient in number and inappropriate in arrangement. For dramatic writing lessons, it was stated that not standard classrooms such as lecture halls or classrooms, but a circular order where face-to-face and non-hierarchical communication is possible is more appropriate. It was also stated as a necessity that the dramatic writing lessons are held on stage from time to time. In addition, the participants emphasized that it is important for students to own their classrooms or studios and feel a sense of belonging. The academic staff of the academic departments that provide dramatic writing education are found to be insufficient. Instructors who teach in this branch also give theoretical lectures. Thus, as the course hour load of the instructors increases, their efficiency decreases and their academic progress slows down. More teaching staff is needed to improve the education. 
Participants stated that the number of student quotas was changed without obtaining opinions from the departments. It has been stated that the ideal number of students for dramatic writing education is ten or twelve. This number is important in terms of evaluating the studies in detail, creating a discussion environment, and allocating time for each student. Thus, it is concluded that the studies are not in the desired quantity and quality. Another point that is emphasized is that the number of applications has decreased over the years. Another point mentioned about the quota is the determination of the candidate profile. It was stated that the majority of applicants did not have the intellectual depth and interest needed for arts education.

It has been observed that the four-year plan for dramatic writing lessons is prepared and maintained with a similar approach in all departments. Career development supports offered to students are student exchange programs, internship and practical work activities and vocational activities. Erasmus programme seems to be weak due to the lack of foreign language. Practical studies and internships reveal that dramatic writing education is seen as a practical education, and that not only text production, but also stage practices and professional performing arts practice are considered important in the career development of students.

Discussion and Conclusion. It can be suggested to arrange classes that allow for a circular seating arrangement that does not have a hierarchical order for dramatic writing education. It also can be suggested to increase the number of teaching staff in order to improve dramatic writing education. In order to increase the quality of the education, the opinions of the departments should be taken into account in arranging the quotas, and the quotas should be limited to ten or twelve. In addition, it can be suggested to inform about the dramatic writing profession within the career planning studies at the high school level. Discovering new fields of study in dramatic writing education, along with the new possibilities of performing arts, and including them in the scope of education is one of the points that can be recommended. Collaboration of departments with arts organizations and institutions will improve the quality of education and students.

Considering that the topics in the study are directly related to learning performance, it is necessary to review the problems in dramatic writing education and to find solutions by discussing them with academic meetings or workshops. 


\section{Giriş}

Ülkemizde 1964 yılında Ankara Üniversitesi Dil ve Tarih Coğrafya Fakültesi çatısı altında başlayan akademik düzeydeki Dramatik Yazarlık Eğitimi 57 yıllık bir geçmişe sahiptir (Nutku, 1983). Dünyadaki örneklerle kıyaslandığında ülkemizdeki eğitim neredeyse yarım yüzyıllık bir gecikmeye sahip olsa da aradan geçen zamanın eğitimde bir standart yaratmak için yeterli olduğu söylenebilir. Bununla beraber yarım yüz yıllık sürecin gelişen teknolojiler ve dönüşen toplumsal koşullar karşısında programın bazı bileşenlerinin eskiyip işlevini yitirmesi için de etkili bir süre olduğunu belirtmek gerekir (Demirel, 2015). Eğitim, doğası gereği geliştirilmeye, güncellenmeye ihtiyaç duyan bir yapıdır. Alanda yapılan sınırlı sayıdaki çalışma da Dramatik Yazarlık Eğitim programlarında çağdaş eğitimin gereklilikleri çerçevesinde yenilenme ihtiyacına işaret etmekte, eğitim programlarının karşılaştırmalı olarak irdelenmesinin bu konuda önemli bir başlangıç olacağı belirtilmektedir (Belkıs, Gümüş, Şaşmaz ve Alpan, 2019).

Birçok alanda olduğu gibi eğitim bilimleri alanında da araştırma geliştirme çalışmalarının hız kazanmasıyla birlikte planlama, geliştirme, hedef belirleme, organizasyon, yaygınlaştırma kavramları öne çıkmaktadır (Demirel, 2015). Ülkemizde ve dünyada yaşanan teknolojik gelişmelerin kuram ve uygulama arasındaki makasın gittikçe açılmasına neden olduğu söylenebilir. Bu sorunu odağa alan tüm programlarda stratejik planlamalar ve geleceğe yönelik iyileştirmeler çağdaş eğitimin doğal bir sonucu olarak karşımıza çıkmaktadır. Küresel pandemi nedeniyle zorunlu olarak geçilen uzaktan eğitim süreci dijital araçların eğitimdeki önemini yeniden gözler önüne sermekle kalmamış eğitimde program iyileştirmenin rotasını da belirlemiştir. Özellikle değişen toplumsal, kültürel ve teknolojik gelişmeler çerçevesinde kuram ve uygulama arasındaki bağın canlı tutulması çağdaş eğitimin öncelikleri arasına girmiştir. Bu bağlamda dramatik yazarlık programlarının mevcut fiziksel koşullarının belirlenmesi çağın isterlerine uygun program iyileştirmenin ilk adımı olarak karşımıza çıkmaktadır.

Dramatik yazarlık ve yazarlık eğitimi bağlamında alan yazına bakıldığında çalışmaların daha çok "yazma" üzerine odaklandığı görülür. Türkiye'de yazarlık üzerine üretilen ilk eserler, dersi veren akademisyenler tarafından, dramatik metnin özellikleri ve tema, olay dizisi, kişileştirme, aksiyon gibi dramatik unsurların açıklandığı çalışmalardır (Özakman, 2001; Nutku, H., 1999; Nutku, Ö., 1965; 1960). Tiyatro Araştırmaları Enstitüsü’nün ilk sempozyumu da “Tiyatro Öğretimi ve Eğitimi” başlığıyla gerçekleştirilmiş, akademide ve uygulamada yer alan tiyatro insanları bir araya gelmiştir (Tiyatro Araştırmaları Dergisi, 1978). Son yıllarda oyun yazarlığına ilişkin teknik ve güncel yaklaşımların irdelendiği çalışmalar (Belkıs, 2020; Arıcı, 2020) kadar, Dramatik Yazarlık Eğitimi üzerine yerel ve ulusal araştırmaların yapıldığı araştırmalar (Belkıs ve Şaşmaz vd., 2019; Belkıs ve Gümüş vd., 2019) da dikkati çekmektedir. Eğitim, psikoloji, edebiyat, sinema gibi alanlarla oyun yazarlığını kesiştiren disiplinlerarası yaklaşımlar taşıyan çalışmalar da alan yazında dikkati çekmektedir (Belkıs ve Gümüş, 2020; Bıçakçı, 2017; Gülsoy, 2013).

Dramatik Yazarlık Eğitimi farklı açılardan araştırılmaktadır; geliştirilmesi için verimli ve anlamlı tartışmalara ihtiyaç vardır. Bu tartışmaların üretilebilmesi içinse öncelikle halihazırdaki olanakların araştırılarak ortaya konulması gerekmektedir. Tüm bunlardan yola çıkarak araştırmamızın amacı, lisans düzeyinde Dramatik Yazarlık Eğitiminin kurumsal olanak ve ihtiyaçlarını belirleyerek bir durum tespiti yapmak olarak belirlenmiştir. Araştırmada kurumsal yapıya ilişkin mevcut demografik verilerin toplanması, böylece yukarıda belirtilen ihtiyacın karşılanmasına katkıda bulunmak hedeflenmiştir. Bu bağlamda temel araştırma sorusu "Dramatik Yazarlık Eğitimi sürdüren akademik birimlerin kurumsal olanak ve ihtiyaçları nelerdir?" olarak ortaya konmuş, alt araştırma soruları ise şöyle planlanmıştır:

Birimler ne zaman ve kimler tarafından kurulmuşlardır? 


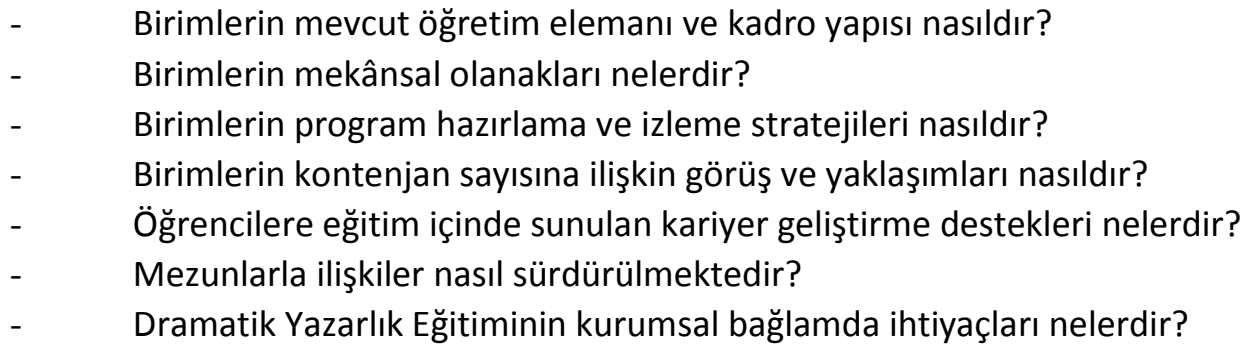

\section{Yöntem}

Araştırmamızda nitel araştırma yöntemi, durum çalışması deseninde kullanılmıştır. Nitel araştırma sosyal yaşamın doğasını incelemek için kullanılan çeşitli yaklaşımların genel adıdır. Saldaña (2011) nitel araştırmayı bir şemsiye kavram olarak nitelendirmiş, veriyi toplama ve analiz etmede sayısal olmayan yöntemlerin kullanılması olarak çerçevelemiştir. Saldaña'ya göre transkripsiyonu yapılmış görüşmeler, saha notları, sanat eserleri, fotoğraf, video kayıtları, internet siteleri ve insan deneyimlerini içeren her türlü belge nitel araştırmaların kaynaklarıdır.

Nitel araştırmalar konunun odak noktasına ve konunun ihtiyacı olan araştırma yaklaşımına göre (oto)etnografi, anlatı, durum, fenomenoloji, gömülü kuram gibi çeşitlilik gösterirler. Burada hem uzmanların kendi kullandıkları terimlerde hem de dilimize yapılan çevirilerde farklı ifadelerle karşılaşılabildiği belirtilmelidir. Nitel yaklaşımları Saldaña'nın (2011) tür (genre), Creswell'in (2013) desen (design) olarak nitelemesi; gounded theory'nin gömülü kuram, kuram oluşturma ve case study'nin de örnek olay, durum çalışması olarak farklı şekillerde çevrildiği hatırlanabilir.

Bu araştırmada durum çalışması (case study) deseni kullanılmıştır. Saldaña (2011) durum çalışmasının ayırıcı özelliğinin analizin tek bir birime -bir kişi, bir grup, bir olay, bir organizasyon, vb.odaklanmak olduğunu; amacın bir tartışma üretmek değil, seçilen odağı derinlemesine incelemek olduğunu belirtmiştir. Buradan hareketle çalışmamızda Türkiye' de lisans düzeyinde Dramatik Yazarlık Eğitimi veren akademik birimlerin 2019 güz dönemi eğitim koşulları durum olarak saptanmış, Creswell'in (2013) araştırma prosedürü benimsenmiştir. Bu prosedüre göre araştırma probleminin durum çalışması yaklaşımına uygunluğu sınanmış, durum belirlenmiş, veri toplama stratejilerine ve analiz yaklaşımına karar verilerek yorumlama süreçleri izlenmiştir. Buna göre araştırmanın yöntemsel yapılandırması şöyle kurgulanmıştır:

\section{Çalışma Grubu ve Verilerin Toplanması}

Bu araştırmaya Türkiye'de lisans düzeyinde Dramatik Yazarlık Eğitimi veren 8 üniversitenin akademik biriminden 7'si katılmıştır. Çalışma grubunu Ankara Üniversitesi, Atatürk Üniversitesi, Dokuz Eylül Üniversitesi, İstanbul Üniversitesi, Kocaeli Üniversitesi, Süleyman Demirel Üniversitesi, Yüzüncü Yıl Üniversitesi oluşturmaktadır. Çalışmanın bilgi kaynağı teknik ve birim yöneticilerinden alınan bilgidir. Birimlere ilişkin demografi, birim yöneticilerinden doğrudan alınmıştır. Yöntemsel olarak görüş inceleme, deneyim paylaşımı bağlamında fenomenolojik bir çalışma olmadığından, birim yöneticilerinden toplanan veriler yeterli görülmüştür. Veriler, çalışma grubunu oluşturan akademik birimlerin bölüm başkanları veya anasanat dalı başkanları ile dokuz sorudan oluşan yapılandırılmış derinlemesine görüşmelerle toplanmıştır. 4 bölüm başkanı ile 210 dakika, 2 ana sanat dalı başkanı ile 150 dakika, 1 öğretim görevlisi ile 20 dakika olmak üzere toplam 380 dakika görüşme yapılmıştır. Bu görüşmeler katılımcıların izniyle kaydedilmiş, görüşmeyi gerçekleştiren araştırmacılar tarafından deşifre edilmiş, analiz için hazırlanmıştır. 


\section{Verilerin Analizi}

Araştırmada toplanan veriler araştırma soruları bağlamında yatay bir anlayışla iki araştırmacı tarafından işbirlikli kodlama ile analiz edilmiştir. İşbirlikli kodlama, araştırma ekibi içindeki birden fazla araştırmacının veri üzerinde birlikte çalışmaları ve içeriğin irdelenmesidir. Süreçte, Saldaña'nın (2019) getirdiği kodlayıcılar arası tutarlılık ya da yorum uyumu gibi ölçütler göz önünde bulundurulmuştur. Kodlayıcılar arası tutarlıık (Miles ve Huberman, 2016) tamdır. Yapılandırılmış sorulara verilen yanıtlar betimsel bir analitik anlayışla sunulmuştur.

\section{Bulgular}

Araştırmanın bulguları, belirlenen amaç doğrultusunda kurgulanan araştırma soruları bağlamında birimlerin kuruluşları ile kadro, kontenjan, mekân yeterlilikleri, program hazırlama ve izleme stratejileri, kariyer geliştirme ve mezun ilişkileri başıklarında sunulmuştur.

\section{Dramatik Yazarlık Birimlerinin Kuruluşu}

Türkiye'de dramatik yazarlık alanında anasanat dalı düzeyinde kurulan ilk birim 1976'da Prof. Dr. Özdemir Nutku tarafından Ege Üniversitesi bünyesinde kurulmuş, daha sonra Dokuz Eylül Üniversitesi'ne aktarılmıştır. Sahne ve Görüntü Sanatları adıyla kurulan bölüm üç anasanat dalı olarak planlanmış, bu yapı bugüne kadar gelmiştir. Kuruluşundan itibaren dramatik yazarlık dersleri çeşitli dönemlerde Özdemir Nutku, Turgut Özakman, Hülya Nutku, Murat Tuncay, Önder Paker, Erdoğan Aytekin, Efdâl Sevinçli, Haluk Işık, Zerrin Akdenizli tarafından verilmiş, ayrıca pek çok konuk öğretim elemanı da oyun yazarlığı derslerine katkıda bulunmuştur. Türkiye'de lisans düzeyinde tiyatro eğitiminin öncüsü olan Ankara Üniversitesi Dil ve Tarih Coğrafya Fakültesi Tiyatro Kürsüsü 1964'te lisans eğitimine başlamış olmakla birlikte Dramatik Yazarlık Anasanat Dalı'nın açılması 1987-88 döneminde gerçekleşmiştir. Nutku'nun (1983) aktardığına göre 1958'de Tiyatro Enstitüsü adıyla kurulduğunda ilk yıl Prof. Kenneth Macgowan, ertesi yıl Prof. Grant Redford'un yönetiminde verilen ilk dersler arasında dramatik yazarlık ve dramatik yapı bilgisi vardır. Bölümde ders veren Beliz Güçbilmez, Süreyya Karacabey gibi pek çok tiyatro araştırmacısı ve akademisyen Dramatik Yazarlık Eğitimine katkıda bulunmuşlardır.

Dramatik Yazarlık Eğitimine ilişkin üçüncü adım Atatürk Üniversitesi'nde Edebiyat Fakültesi bünyesinde atılmış, 1993 yılında Güzel Sanatlar Fakültesi bünyesine geçerek Prof. Dr. Özdemir Nutku ve Prof. Dr. Murat Tuncay'ın desteğiyle açılan Sahne Sanatları Bölümü kapsamında Dramatik Yazarlık Anasanat Dalı kurulmuştur. Nutku ve Tuncay'ın konuk öğretim üyesi olarak katkı verdikleri anasanat dalında Sema Göktaş, Erbil Göktaş ve Birgül Yeşiloğlu kurucu öğretim elemanı olarak yer almışlardır. 1997'de Süleyman Demirel Üniversitesi'nde Tiyatro Bölümü adıyla kurulan bölüm ve oyun yazarlı̆̆ı eğitimi, 2002'de Dramatik Yazarlık Anasanat Dalı olarak revize edilmiş ve Önder Paker kurucu öğretim elemanı olarak rol almıştır. Bu girişimleri 2004'de Kocaeli Üniversitesi'nde Sema Göktaş ve Erbil Göktaş tarafından kurulan anasanat dalı ile 2008'de İstanbul Üniversitesi'nde kurulan Dramaturji ve Dramatik Yazarlık Sanatı Ana Bilim Dalı takip etmiştir. Yavuz Pekman ve Oğuz Arıı’nın yazarlık derslerini yürüttüğü bu anasanat dalı, aslında 1992'de Zehra İpşiroğlu tarafından kurulmuş Tiyatro Eleştirmenliği ve Dramaturji Bölümü’ne bağlıdır. Dramatik Yazarlık Eğitiminde son adım Yüzüncü Yıl Üniversitesi Güzel Sanatlar Fakültesi'ne bağlı olarak 2016'da kurulan ve eğitime 2020'de başlayan, kurucu kadrosunda Funda Özşener ile Filiz Keskin'in bulundukları anasanat dalıdır

Toplanan bilgilere bakıldığında oyun yazarlığı eğitiminde akademik birim başlığının tüm üniversitelerde ortak olduğu burada belirtilebilir. Ayrıca Dokuz Eylül Üniversitesi Sahne Sanatları Bölümü’nün, başka birimlerin kurulmasında, bu bağlamda eğitim öğretim programlarının ve 
akademik yapılanmanın tutarlılı̆ında etkin olduğu da görülmektedir. Bunun yanında Atatürk Üniversitesi'nde Dramatik Yazarlık Eğitimini başlatan Sema Göktaş ve Erbil Göktaş'ın Kocaeli Üniversitesi'nde muadil birimi kurdukları, bu bakımdan da bölümler arasında organik bir bağ oluştuğu söylenebilir. Araştırmaya katılan akademik birim sorumluları, hayatta olan kurucu öğretim üyeleriyle iletişimlerinin kişisel ilişkiler düzeyinde devam ettiğini, akademik bağlantının bulunmadığını belirtmişlerdir.

\section{Kadro Yeterlilikleri}

Dramatik yazarlık anasanat dallarının kadro bağlamıyla ilgili bulgular kadro kapasiteleri ve kadro yeterliliği olmak üzere iki bölümde sunulmuştur.

Araştırmaya katılan dramatik yazarlık anasanat dallarında 2020 güz dönemi itibarıyla toplam 33 öğretim elemanı bulunmaktadır ve kadro kapasitesi şöyledir: Dokuz Eylül Üniversitesi'nde 7, Ankara Üniversitesi'nde 3, Atatürk Üniversitesi'nde 6, Süleyman Demirel Üniversitesi'nde 4, Kocaeli Üniversitesi'nde 7, İstanbul Üniversitesi'nde 4, Yüzüncü Yıl Üniversitesi'nde ise 4 öğretim elemanı ile Dramatik Yazarlık Eğitimi sürdürülmektedir. Dramatik yazarlık anasanat dallarına ilişkin kadro dağılımı Tablo 1'de sunulmuştur.

Tablo 1.

Türkiye Üniversitelerinde Dramatik Yazarlık Anasanat Dalı öğretim elemanlarının kadro dağılımı

\begin{tabular}{|c|c|c|c|c|c|c|}
\hline & Profesör & Doçent & $\begin{array}{l}\text { Dr. } \\
\text { Öğretim } \\
\text { üyesi }\end{array}$ & Öğr. Gör. & Araş. Gör. & Toplam \\
\hline Dokuz Eylül Üniversitesi & 2 & 2 & 2 & - & $1 *$ & 7 \\
\hline \multirow[t]{2}{*}{ Ankara Üniversitesi } & - & - & 1 & 1 & - & 3 \\
\hline & & & & $1 * *$ & & \\
\hline Atatürk Üniversitesi & - & 2 & 1 & 1 & 2 & 6 \\
\hline Süleyman Demirel Üniversitesi & & & 1 & 2 & $1 *$ & 4 \\
\hline Kocaeli Üniversitesi & 1 & - & 1 & $3^{* *}$ & - & 7 \\
\hline İstanbul Üniversitesi & - & 3 & - & - & 1 & 4 \\
\hline Yüzüncü Yıl Üniversitesi & - & 1 & 3 & - & - & 4 \\
\hline Toplam & 3 & 8 & 9 & 8 & 5 & 33 \\
\hline
\end{tabular}

* ÖYP kadrosu

** ders saati ücretli öğretim görevlisi

Tablo 1'de sunulan akademik birimler, aktif olarak Dramatik Yazarlık Eğitimi vermekte olan birimlerdir. Bir akademik birimin araştırmaya katılmadığı, kuruluşu gerçekleşmiş olsa da henüz öğrenci kabul etmeyerek eğitime başlamayan birimlerde de az sayıda kadronun bulunduğu hatırlanabilir. Bunların dışında somut veri olarak yukarıda tabloda yer alan üniversitelerin kadroları ise şöyledir: Semih Çelenk, Aslıhan Ünlü, Özlem Belkıs, Banu Ayten Akın, Uğur Akıncı, Yasemin Sevim Salman, Yunus Emre Gümüş Dokuz Eylül Üniversitesi'nde; Duygu Teksoy Ceber, Ozan Utku Akgün, Sıtkı Tekmen Ankara Üniversitesi'nde; Bünyamin Aydemir, Tamer Temel, Elif Candan, Ezgi Deniz Alpan, Erdoğan Göğebakan, Cem İçyar Atatürk Üniversitesi'nde; Müşerref Öztürk Çetindoğan, Evren Nazım Arat, Fazilet Demirdaş, Şifa Kayabaşı Süleyman Demirel Üniversitesi'nde; Sema Göktaş, Erbil Göktaş, Ayşegül Yıldız Ulaş, Ali Ömür Ulusoy, Oktay Emre Kocaeli Üniversitesi'nde; Yavuz Pekman, Hasibe Kalkan Kocabay, Oğuz Arıcı, Nihan Şentürk İstanbul Üniversitesi'nde; Funda Özşener, Filiz Keskin, Sabri Şenol, Barış Mutlu Yüzüncü Yıl Üniversitesi'nde dramatik yazarlık anasanat dalı kadrosunda bulunmakta, alan derslerini vermektedirler. 
Katılımcıların verdikleri bilgilere dayanarak kadro yeterlilikleri hakkındaki görüşler ise şöyle sunulabilir: Sadece bir anasanat dalında kadro sayısının yeterli olduğu, diğer yedi anasanat dalında ise yetersiz bulunduğu ortaya konmuştur. Kadro sayısının yetersizliği katılımcılar tarafından neden ve sonuçlarıyla birlikte ortaya konmuştur. Değinilen ilk nokta ders saati yüklerinin fazlalığıdır. Dramatik yazarlık alanında ders veren öğretim elemanlarının aynı zamanda sahne sanatları alanının oyun incelemesi, tiyatro tarihi gibi kuramsal derslerini üstlenmeleri nedeniyle ders saati yüklerinin yoğun olması, dolayısıyla sadece dramatik yazarlık alan derslerine odaklanmıyor olmaları vurgulanmıştır. Bu yoğunluk, öğretim elemanlarının kendi akademik çalışmalarına yeterince zaman ayıramamalarına, dolayısıyla da akademik yükselmelerin yavaş olmasına ya da durmasına neden olmaktadır. Öğretim elemanlarının ders saati yüklerinin fazlalığının verimliliği düşürdüğü bu konudaki önemli bir sorun olarak dile getirilmiştir. Kadro yetersizlikleri konusunda dile getirilen ikinci nokta, öğretim elemanı yetiştirmedeki sıkıntılardır. Anasanat dallarına asistan alınmaması yanında ÖYP (öğretim elemanı yetiştirme programı) kadrosuyla bölümlere gelen asistanların, lisans üstü eğitimlerini tamamladıktan sonra kendi üniversitelerine dönmeleri, böylece anasanat dalında yetiştirilen öğretim elemanlarının kalıcı olamadığı ve anasanat dallarının bu şekilde 'eridiği, kan kaybettiği' bir kadro problemi olarak dile getirilmiştir. Öte yandan ÖYP ile hedeflenen kadro hareketliliğinin anasanat dalı bağlamında aidiyet duygusu ya da bağ kurulmasını zorlaştırdığı da vurgulanan bir konudur. Kadro konusunda dile getirilen üçüncü noktanın uzmanlık alanı olduğu görülmektedir. Dramatik yazarlık alanında uzman kişilerin ders saati ücretli öğretim görevlisi olarak İstanbul dışındaki üniversiteler için görevlendirilmeleri bir problem olarak dile getirilmiştir. Bunun yanında anasanat dalının kadro ihtiyacını fakülte ya da üniversite içinden karşılamak için farklı bölümlerden öğretim elemanlarına başvurulması da alan uzmanlığı konusunda dile getirilen bir başka husustur. Bu noktada özellikle doğudaki üniversitelerin kadro bakımından desteklenmeleri gereği de dile getirilmiştir. Dramatik yazarlık alanında kadro konusunda dile getirilen dördüncü nokta ise dört yıllık eğitim boyunca öğrencinin yazarlık dersini farklı öğretim elemanlarından almasının önemi, bu bağlamdaki kadro çeşitliliği meselesidir.

\section{Mekânsal Olanaklar}

Dramatik yazarlık anasanat dallarının fiziksel koşulları bağlamında ders mekanları konusunda toplanan bilgiler mekanların yeterli olup ihtiyacı karşıladığı ve karşılayamadığı şeklinde iki bölümde değerlendirilebilir. 3 katılımcı genel olarak yazarlık dersleri için tahsis edilen mekanların yeterli olduğunu, bu mekanlarda projeksiyon, tahta gibi teknolojik sınıf araçlarının bulunduğunu, öğrenci sayısına oranlanınca da mekanların yeterli olduğunu açıklamışlardır.

"Dramatik yazarlık derslerini ya hocanın odasında ya da küçük sınıfımızda sürdürüyoruz. Mekân konusunda Oyunculuk anasanat dalının öncelikli olduğunu düşünüyoruz çünkü fiziksel olarak mekâna daha çok ihtiyaç duyan anasanat dalı. Yazarlık anasanat dalının, en azından şu an için yürüttüğümüz program doğrultusunda, ayrıca bir mekân ihtiyacı olduğunu düşünmüyoruz. Yani söz konusu mekânda çeşitli teknolojik gereçler mevcut, projeksiyon gibi." (K1)

"(...) en rahat olduğumuz şey bu herhalde. Bizim büyükçe bir salonumuz var. Kocaman uzun bir masamız. Bir yazı tahtası, projeksiyon cihazı, çocukların boyadıkları yatay bir raf var. Yani sıcak sevimli bir salonumuz var. Yazarlık derslerini yüz yüze yapmak için bundan daha fazlasına ihtiyaç duymuyoruz." (K5)

Diğer 3 katılımcı ise yazarlık derslerinin herkesin birbirini görebileceği dairesel oturma düzenine sahip özel mekanlara ihtiyaç duyduğunu, bu beklentinin genel olarak karşılanamadığını, ancak standart derslik ya da amfilerin tahsis edildiğini belirtmişler, ders mekanlarının yetersiz olduğunu vurgulamışlardır. Dokuz Eylül Üniversitesi'nin ise araştırmanın yapıldığı dönem için özel bir 
durumunun söz konusu olduğu, fakülte binasının deprem yönetmeliğine uygun olmaması nedeniyle geçici olarak başka bir binada eğitim verildiği eklenmelidir. Dolayısıyla mekânsal koşullar bakımından Dokuz Eylül Üniversitesi burada değerlendirmeye alınmamıştır. Mekânsal yetersizlikler konusunda özellikle hiyerarşiyi ortadan kaldıran, tüm öğrencilerin birbirinin yüzünü gördüğü, topluca katılımla konuşmaya ve tartışmaya izin veren dairesel düzenin gerekliliği vurgulanmıştır. Dramatik Yazarlık Eğitiminin mekânsal ihtiyaçları konusunda, dersi alan öğrencilerin sahiplenebilecekleri bir mekân oluşturulması dile getirilen başka bir husustur. Derslerin zaman zaman sahnede yapılması talebi de belirtilmiştir.

"Sahnede ders yaparım mutlaka. Ders programını ona göre yaptırıım. Yazarlık öğrencisini sahneye indirmek için ders değiştirtirim. (...) oyunun giriş çıkış timingini öğretmek çok zor oluyor kâğıt üstünde." (K6)

"Bir günde on beş bin kişinin girdiği bir fakülteyiz. (...) bize verilen sınıf neresiyse orada ders vermek zorunda kalıyoruz. Bazen sıra düzeninde bazen kolçaklı sandalye düzeninde. Eğitime ilk başladığımızda ideal olarak yuvarlak masada ders yapıyorduk. (...) Şimdi maalesef sınıf düzeninde ders yapıyoruz ve bu hiç uygun değil." (K4)

"Bu sınıflar hem yazarlık dersinin yapıldığı hem de kuramsal derslerin yapıldığı sınıflardır. Dolayısıyla maalesef sadece yazarlığın stüdyo olarak kullandığı bir mekânımız yok. (...) kuramsal derslerin yapıldığı, tek kolçaklı sandalyelerin olduğu bir sınıfta yazarlık dersi yapıyoruz. (...) sıralı düzende oturulmaz yazarlık derslerinde, herkesin birbirini görmesi istenir. Biz başka bir mekânı tahsis ettiremiyoruz kendimize çünkü bölüm dağılır hale gelirse fakültede öğrencinin aidiyet duygusu da tuhaflaşmaya başlıyor. Çünkü biz bir çatı altında Sahne Sanatları Bölümü sınırları içinde yaratılsın istiyoruz bu sınıflar, stüdyolar. O da maalesef fakülte binasının yetersizliği yüzünden gerçekleşemiyor. (K6)

Katılımcıların Dramatik Yazarlık Eğitiminde mekânsal ihtiyaçları dile getirirken öğrencinin aidiyet duygusunun oluşması, hiyerarşinin ortadan kaldırılması gerekliliğine vurgu yaptıkları görülmektedir. Bu bağlamda mekânlara öğrencinin mesleki eğitiminde oldukça önemli bir işlev yüklendiği anlaşılmaktadır.

\section{Program Hazırlama ve İzleme Stratejileri}

Dramatik Yazarlık Eğitimi için program hazırlama izleme stratejileri dramatik yazarlık derslerinin dört yıllık planı, diğer yaratıcı yazarlık dersleri ve mesleki kuramsal dersler olmak üzere üç bölümde değerlendirilmiştir. Dramatik yazarlık derslerinin dört yılık planı bağlamında tüm anasanat dallarında benzer bir yaklaşımla hazırlanıp sürdürüldüğü, tür ve konu çerçevesi bakımından üçüncü sınıfa kadar temel dramatik yapı üzerinde durulduğu, Aristotelesçi gerçekçi tiyatronun ele alındığı, üçüncü sınıftan itibaren Aristotelesçi olmayan, absürt, soyutlama ya da groteske dayanan veya Postdramatik üsluplara yaslanan oyunların çalışılabildiği görülmüştür.

"Programımız Aristotelesçi, dramatik tiyatro üzerine çünkü ana damarı öğrenmelerini istiyoruz. Bu ana damarı öğrendikten sonra buna alternatif olarak ne tarz istiyorlarsa yapabilirler." (K4)

"1. ve 2. Sınıfta iyi kurulu oyun üzerine çalışıyoruz daha çok. O temel yapıyı tanımaları adına. Karşı çıkacaklarsa da sahipleneceklerse de mutlaka o temel yapı üzerine bir fikir sahibi olmalarını istiyoruz. Onun için 1. Ve 2. Sınıfta birtakım sınırlamalarımız var ama 2. Sınıftan itibaren tür denemelerine başlayabiliyorlar". (K1) 
"1.sınıfta temel yaratıcı yazarlıkla başlıyoruz ilk yarıyılda. Bu sınıfın hedefi sahne için yazmaya yönelik. (...) 2. Sınıfta gerçekçi tiyatroda karakter inşası üzerine duruyoruz. Az çok kurgu becerisi edinmiş oluyor çocuk. Nihai hedefi 2. Sınıfın bu ve yine sahne için yazıyor. 1 ve 2. Sınıfın odağı sahne için yazmak. 3. Sınıf görüntü eğitimi. Sinema ve TV yazarlığı burada... senaryo yazma üzerinde duruluyor." (K5)

Tüm dramatik yazarlık anasanat dallarının bir başka ortak yaklaşımı ise diğer yaratıcı yazarlık derslerini de programlarına almış olmalarıdır. Anasanat dallarının farklı sınıf düzeylerinde senaryo, televizyon, radyo, reklam yazarlığı ile yazınsal türler ve anlatım derslerinin sürdürüldüğü belirtilmiştir. Araştırmamızın kapsamındaki tüm anasanat dallarında Türk ve Dünya tiyatrosu üzerine genel meslek derslerinin çeşitliliğine duyulan ihtiyaca vurgu yapıldığı görülmüştür. Fakat bu çeşitliliği karşılayacak öğretim elemanı olmadığı da burada dile getirilmiştir.

\section{Kontenjana İlişkin Görüşler}

Dramatik yazarlık ana sanat dallarının kontenjanlarına ilişkin sayısal veriler üç üniversitede aynı, diğerlerinde değişiklik göstermektedir. Türkiye üniversitelerinde lisans düzeyinde eğitim verilen dramatik yazarlık ana sanat dallarının öğrenci kontenjanları Tablo 2'de sunulmuştur.

Tablo 2.

Türkiye üniversitelerinde Dramatik Yazarlık Anasanat Dalı kontenjanları

\begin{tabular}{lc}
\hline Üniversite & $\begin{array}{c}\text { Kontenjan } \\
\text { Sayısı }\end{array}$ \\
\hline İstanbul Üniversitesi & 30 \\
Kocaeli Üniversitesi & 15 \\
Dokuz Eylül Üniversitesi & 12 \\
Atatürk Üniversitesi & 10 \\
Süleyman Demirel Üniversitesi & 10 \\
Yüzüncü Yıl Üniversitesi & 10 \\
Ankara Üniversitesi & 5 \\
\hline Toplam & 92 \\
\hline
\end{tabular}

Araştırmamızın katılımcıları anasanat dallarının kontenjan sayılarının kendi düşünce, öneri ve kararlarından bağımsız olarak değiştirildiğini belirtmişlerdir. 5 katılımcı kontenjan sayısının önceki yıllarda bölümlerden görüş alınmaksızın YÖK tarafından artıııldığını vurgulamıştır. Yalnızca 1 katılımcı (Süleyman Demirel Üniversitesi) kontenjan sayısının bölümün talebi üzerine artırıldığını belirtmiştir. İkinci katılımcı, bu durumu "Dışarıda kimse kalmasın, herkes üniversiteli olsun düşüncesiyle nicelik olarak" artırıldığını belirterek bu konudaki endişesini dile getirmiştir. 3 katılımcı ise kontenjan sayılarının bölüm bazında kullanımının başvuru sayılarına, aday profillerine göre değişkenlik gösterebildiğini; başvurunun fazla ya da az gelmesi durumunda kontenjanın bölümün diğer anasanat dalları ile paylaşılabildiğini belirtmiştir. Öğrenci kontenjanlarının anasanat dalları için önemli bir konu olduğu, Dramatik Yazarlık Eğitiminde kontenjan artışıyla nitelik korumanın zorlaşacağına dair bir endişe olduğu da burada belirtilmelidir.

"Etkileşimde bulunmak, ders yapmak, bilgi alışverişi yapmak zor oluyor. (...) Dramatik yazarlık sınıfı açısından ideali on, on iki kişidir. Çünkü bu işin bir mesaisi var. Öğrenciye bir şey yazdırıp, toplayıp, okuyup feedback vermek zor oluyor. Herkes otuz sayfa yazsa üç yüz sayfa yapıyor. Bir kitap boyutunda... Bu sayı on beşe çıktığı anda hacim katlanıyor dolayısıyla işleyişe dair sorun oluyor. Dersin içinde de üç saat gibi bir kısıtlamamız var. On kişiye ayrılacak vakitle on 
beş kişiye ayrılacak vakit arasında verimlilik bakımından fark oluyor tabii ki. Fakülte on kişinin altında kontenjanla ders açmama kararı aldı örneğin bir ara. Pek çok bürokratik zorluk yaşanıyor." (K4)

"Hala makul ölçülerin içindeyiz. Ama mesela oyunculukta yazarlıkta bu 12, 15 olursa, 20 olursa her şey çığırından çıkmaya başlar. Çünkü şunu anlamıyor olabilir dışarıdan bakanlar. Nasıl yani 12 kişilik eğitim, böyle lüks bir şey olabilir mi, n'apıyorsunuz siz böyle denilebilir. Ama gerçekten biz sanat eğitimi yapıyoruz o biricik bir kişinin çıkması için uğraşıyoruz. O kişi uniqe, yegane... Biz onun formasyonunu tamamlamaya çalışıoruz." (K3)

Bu verilerden yola çıkarak değinilen ilk nokta bir sınıftaki ideal öğrenci sayısının on kişi olduğu yönündedir. Dramatik yazarlık derslerinin tartışma ve değerlendirme ortamına ihtiyaç duyan doğası vurgulanmıştır. Ilerleyen yıllarda eğitimi bırakan ya da ara veren öğrenciler nedeniyle mevcut sayının azalması, söz konusu atölye ortamının oluşmasının önünde bir engel olarak görülmektedir. Kontenjana ilişkin görüşler konusunda değinilen ikinci nokta Dramatik Yazarlık Eğitiminin öğrenciyle birebir ilgilenmeyi gerektiren yapısı gereği, fazla sayıda öğrenci olduğunda öğretim elemanının gerekli verimi gösteremediği, değerlendirme süresinin uzadığı, böylece yapılan çalışmaların istenen nicelikte ve nitelikte olamadığıdır. Bu verilere ilişkin görüşlerde vurgulanan üçüncü nokta başvuru sayısının yıllar içinde azaldığıdır. Kontenjan sayısı artırılırken başvuru sayısının azalması bir uyumsuzluk olarak karşımıza çıkmaktadır. Dramatik Yazarlık Eğitimi kontenjanına dair değinilen dördüncü noktanın ise aday profiline dair olduğu görülmektedir. Özel bir birikim ve yaklaşım gerektiren Dramatik Yazarlık Eğitimini almak isteyen adayların bir kısmında 'entelektüel derinleşme' problemi görüldüğü de vurgulanmıştır.

"Doğru dürüst bir orta öğretime ihtiyaç var. Buralardan gelen öğrencilerin temel bilgileri eksik: mantık, sosyoloji, felsefe, edebiyat mı öğretiliyor bu çocuklara? Bunlar yok... Yazarlık dediğimiz şey hem bir temel bilgiye hem de tiyatro nosyonuna ihtiyaç duyar. Bize tiyatroya hiç gitmemiş insan geliyor" (K4).

"Şimdiki nesilde yelpaze geniş, hız fazla ama tahammül bir parça az. Bizim işimizin sabır işi olduğunu düşünürsek hani tıpkı taş işşisi gibi işte oltu taşını işleyen gibi, ya da telkâri iş̧̧isi gibi... bizimki tamamen sabır işi. Bir lafı oradan kaldırıp öteki tarafa koyduğunda anlam tamamen değişir, o karakter o karaktere o lafı söylemediğinde... Bütün bunlar sabır ve yeniden yeniden yeniden bakma ve iş̧̧ilik" (K3).

Tüm bunlardan ve aktarılan örneklerden anlaşıldığı gibi Dramatik Yazarlık Eğitiminde öğrencinin mesleki gelişimi, birey odaklı bir eğitim çerçevesinde kurgulanmaktadır. Bu nedenle kontenjan artışının çeşitli sorunlara ve eğitimdeki kalite kaybına neden olduğu genel bir kanı olarak görülmektedir.

\section{Kariyer Geliştirme Destekleri}

Dramatik yazarlık öğrencilerine sunulan kariyer geliştirme destekleri öğrenci değişim programları, staj ve pratik çalışma faaliyetleri ve mesleki etkinlikler olarak üç başlıkta incelenebilir. Dramatik Yazarlık Eğitimi veren anasanat dallarından 4'ü öğrenci değişim programı olarak Erasmus ve Farabi'nin üniversite ve fakültelerinde uygulandığını, bu şekilde öğrencilere yurtdışında ve yurtiçinde eğitim deneyimi olanağı sunulduğunu belirtmişlerdir. Diğer 3 katılımcı bu değişim programlarından henüz faydalanmadıklarını açıklamışlardır. Bunun bir nedeni yabancı dil öğrenmekteki yetersizliğin Erasmus hareketliliğinden faydalanmak için bir engel olduğudur. 
2 katılımcı hariç tüm katılımcılar öğrencilere kariyerler gelişimleri için eğitim dışı destekler sunduklarını dile getirmişlerdir. Burada eğitim dışı desteklerden kasıt, söyleşi ve atölye çalışmalarıdır. Burada, Dokuz Eylül Üniversitesi'nde 38 yıldır Türkiye'deki tüm dramatik yazarlık öğrencilerinin katılımına açık olarak Suat Taşer Kısa Oyun Yazma Yarışması düzenlediği, yazarlık eğitimini sürdüren öğrencilerin bu yarışma ve sonrasındaki sahneleme pratikleri açısından çok faydalı olduğu da belirtilmelidir. 3 katılımcl, eğitim süreci devam eden öğrencilerini özel ya da kurumsal tiyatrolara kişisel bağlantıları aracılığıyla yönlendirdiklerini, bu yolla öğrencilerin deneyim ve birikimlerine destek olduklarını belirtmişlerdir.

\begin{abstract}
"Mesela Devlet Tiyatrosu'na bir yönetmen geliyor, onu hemen okula davet edip söyleşi ya da workshop yapıyoruz. Ya da yetenek sınavlarımıza dışarıdan hocalar geldiğinde konferans, workshop gibi etkinlikler yapıyoruz. Buraya gelenler sanatçıları, akademisyenleri değerlendiriyoruz" (K2).
\end{abstract}

"Bölümün kuruluşundan beri bazı kurumlarla ilişkileri var. Bu ilişkiler öğrencilerimize hep bazı yollar açtı. Öğrencilerimiz festivallerde çalışır, seminerlerde, atölyelerde görev alırlar. Zaman zaman anket çalışmaları, soruşturmalar yaptığımı oluyor ve öğrencilerimiz de bunda aktif olarak görev alıyor" (K4).

"Biz şunu deriz, bunu götür Devlet Tiyatrosu'na ver, posta kağıdını bize getir ya da mesela alırız teksti, bir yönetmen arkadaşımıza yollarız. Çocuk oyunu lazım derler, 4. Sınıflardan 3. sınıflardan çocuk oyunu olan var mı diye sorarız. Senaryo anlamında destek istenir diyelim $k i$ bir yerden istanbul'dan ya da Ankara'dan, kurumlardan ya da yapım şirketlerinden, hemen birkaç öğrencimizi yönlendirmeye çalışırız" (K3).

Araştırmada Dramatik Yazarlık Eğitimindeki kariyer gelişimi bakımından önemli adımlardan birinin staj ve pratik çalışmalar olduğu 4 katılımcı tarafından vurgulanmıştır. Bu katılımcılar, dramatik yazarlık öğrencilerinin hem eğitim içindeki uygulamalarda yaptıkları pratik çalışmaların hem de profesyonel kurumlarda gerçekleştirilen staj programının önemine değinmişlerdir. Bu vurgular, Dramatik Yazarlık Eğitiminin aktif, uygulamalı bir eğitim olarak görüldüğünü, sadece metin uygulamalarının değil, sahne uygulamalarının ve profesyonel gösteri sanatları pratiğinin de öğrencilerin kariyer gelişimlerinde ve yönelimlerinde önemsendiğini düşündürmektedir.

\title{
Mezunlarla İlişkiler
}

Dramatik yazarlık dalı mezun sayılarına ilişkin olarak net bir bilgiye ulaşılamamıştır. 4 anasanat dalının mezun sayılarına ulaşmak mümkün olmuş, buna göre yaklaşık 900 kişinin bu anasanat dallarından mezun olduğu öğrenilmiştir. Yüzüncü Yıl Üniversitesi'nin henüz mezun vermediği burada belirtilmelidir. Öte yandan mezun verisine ulaşmada karşılaşılan zorluklar ve diğer etmenler göz önünde bulundurulduğunda ise dramatik yazarlık anasanat dalı özelinde birimlerce mezun sayısının kaydını tutan bir sisteme sahip olunmadığı görülmüştür. Katılımcılardan tümü mezun öğrencilerle ilişkilerin kurumsal değil kişisel bağlarla sürdüğünü belirtmişlerdir. 2 katılımcı kurumsal bir iletişim ağı oluşturmak üzere çalışmalar yapıldığını açıklamıştır. Yalnızca 1 katııımcı mezunlarının atölye ve söyleşilere davet edildiğini, Suat Taşer Kısa Oyun Yazma Yarışması'nda jüri olarak değerlendirildiğini, böylece profesyonel iş birliği içinde olduğunu belirtmiştir. 


\section{Dramatik Yazarlık Eğitiminin Kurumsal İhtiyaçları Üzerine Görüşler}

Dramatik Yazarlık Eğitiminin kurumsal ihtiyaçlarına ilişkin görüşler dört tema olarak belirmiştir. Bunlar: öğrenci profili, kadro intiyacı, mekânsal ihtiyaçlar, akademik tartışma ortamı eksikliği.

Katılımcıların öğrenci / aday öğrenci profiline ilişkin sorunları eğitim sistemiyle, çağın ruhuyla ilişkilendirerek değerlendirdikleri görülmüştür. Öğrencilerin çoğunluğunun genel kültür ve entelektüel birikim yönünden zayıf olduklarını, ortaöğretimden yeterli donanımla gelmediklerini vurgulayan katılımcılar, öğrencilerin bu eğitim hakkında yeterli bilgi sahibi olmadan kayıt yaptırdıklarına da değinmişlerdir. 2 katııımcı taşrada sanat eğitimi verilmesinin zorluklarına vurgu yapmıştır. Buna göre sanatsal, sosyal hareketliliğin az olduğu bu şehirlerde öğrenciler kendilerini geliştirmeleri için yeterli olanaklara erişememektedir. Özellikle Anadolu'da ve tiyatrosu olmayan kentlerde yetişmiş, daha önce tiyatro izlememiş öğrencinin eğitime uyum göstermek ve gelişmekte zorluk çektiği de belirtilmiştir.

Dramatik Yazarlık Eğitiminin ihtiyaçları bağlamındaki soruya 3 katıımcının yanıtı akademik personel ihtiyacı üzerinedir. K3 "Dramatik Yazarlık Eğitiminin biricikliği” üzerinde durarak, diğer katıımcıların da vurguladığı noktanın altını çizmiştir. Dramatik yazarık dersi verecek eğiticilerin ders saati ücretli olarak bulunmasının zorluğuna değinilmiştir. Ayrıca birimler kadro sorununa değinirken az sayıdaki bu akademik birimlerde öğretim elemanı yetiştirme stratejilerinin zayıf olduğunu, ÖYP kadrolarının güçlü bölümleri zayıflattığını vurgulamışlardır. Bir başka konu da öğrencinin her dönemde farklı bir öğretim elemanından ders almasının eğitim ve mezun kalitesini artıracağı yöndedir.

Mekân, Dramatik Yazarlık Eğitiminin ihtiyaçları içinde ilk akla gelen konulardan birisi olmuştur. Katılımcılar Dramatik Yazarlık Eğitiminin özel bir alan olarak kabul edilmesi gerektiğini söyleyerek, bürokratik yapıların bunu destekleyecek şekilde işlemesi gerektiğini açıklamışlardır.

Akademik tartışma ortamının eksikliği, Dramatik Yazarlık Eğitiminin ihtiyaçlarından birisi olarak dile getirilmiş, eğitim veren birimlerin ve bu birimlerin akademik kadrolardaki akademisyenlerin sayıca az olması, buna karşın bilimsel toplantı ve etkinliklerin, yani akademik tartışma ortamına intiyaç duyulduğu belirtilmiştir.

\section{Tartışma, Sonuç ve Öneriler}

Sanat eğitimi doğası gereği farklı ve özel koşullara ihtiyaç duyar. Dramatik Yazarlık Eğitimi de gösteri sanatları eğitimi kapsamında özel ve diğer alanlarıyla yoğun etkileşimli bir yere sahiptir. Dramatik Yazarlık Eğitimine odaklanan ve eğitim pratiklerinin koşullarını araştırmayı hedefleyen bu çalışma, "Dramatik Yazarlık Eğitimi sürdüren akademik birimlerin kurumsal olanak ve ihtiyaçları nelerdir?" sorusuna yanıt aramıştır. Elde edilen bulgular araştırmanın sınırlarının belirlendiği öğretim dönemi içinde Dramatik Yazarlık Eğitimine dair bir fotoğraf sunmaktadır. Bu fotoğrafta alanın temel sorun ve tartışmaları, intiyaç ve olanakları belirmiştir.

Dramatik Yazarlık Eğitiminin hem kuramsal hem de uygulama yönü vardır. Bu iki yönlü vazgeçilmez yapı düşünüldüğünde eğitimin kalitesini belirleyenler faktörlerin sayısı da fazladır. Araştırma soruları bağlamında bulgular döküldüğünde beş başlık sonuç cümlesi olarak belirmiş, önem ve yoğunluk sırasına göre sunulmuştur: 1-Mekansal olanaklar, 2-Kadro yeterlilikleri, 3-Kontejanlar, 4Program hazırlama ve izleme stratejileri, 5 - Kariyer geliştirme destekleri. 
1- Dramatik yazarlık anasanat dallarının fiziksel koşulları bağlamında ders mekanları dikkate alındığında sahip olunan ve kullanılan mekanlar Dramatik Yazarlık Eğitimi için uygun ve yeterli değildir. Standart amfi ya da derslik türü mekanların Dramatik Yazarlık Eğitimi için elverişli olmadığı, yüz yüze ve hiyerarşiden uzak bir iletişim mümkün olduğu dairesel düzenin bu derslerin doğası ve yapısı için daha uygun olduğu burada belirtilmelidir. Dairesel oturma düzenine uygun mekanların kullanım gerekliliği yanında dramatik yazarlık derslerinin zaman zaman sahnede yapılması da bir intiyaç olarak dile getirilmiştir. Ek olarak katılımcılar öğrencilerin ders mekanları ile ilişkilerini aidiyet bağlamında değerlendirmişler, öğrencilerin ders mekanları ya da stüdyoları sahiplenmelerinin önemli olduğunu vurgulamışlardır. Kısacası mekanlar sayısal, biçimsel olarak yetersizdir; ders mekânı Dramatik Yazarlık Eğitimi için önemli bir unsurdur.

Dramatik Yazarlık Eğitiminin güçlendirilmesi ve geliştirilebilmesi için hiyerarşik düzene sahip olmayan dairesel oturma düzenine imkân veren, aidiyet duygusu geliştirebileceği mekanlar tahsis edilmesi önerilebilir.

2- Dramatik yazarlık lisans eğitimi veren akademik birimlere tahsis edilmiş kadrolar yetersiz bulunmaktadır. Dramatik yazarlık anasanat dalında ders veren öğretim elemanlarının, kadro yetersizlikleri yüzünden üstlenmek zorunda kaldıkları sahne sanatlarının kuramsal dersleri ders saati yüklerini artırmaktadır. Bu durum da öğretim elemanlarının dramatik yazarlık branş derslerine ilişkin verimlerinin düşmesinin ve akademik yükselmede gecikmelerinin önemli nedenlerinden biri olarak görülmektedir. Dramatik Yazarlık Eğitiminin geliştirilmesi ve güçlendirilebilmesi için daha fazla sayıda öğretim elemanı kadrolarının tahsis edilmesine intiyaç vardır.

Dramatik Yazarlık Eğitiminin geliştirilebilmesinin etkenlerinden birisi olarak öğretim kadrolarının sayıca artırılması önerilebilir.

3- Kontenjanlar başlığında ise katılımcılar anasanat dallarının öğrenci kontenjan sayılarının bölümlerden görüş alınmaksızın değiştirildiğini belirtmişlerdir. Elde edilen bulgular, Dramatik Yazarlık Eğitimi için ideal öğrenci sayısının on, on iki kişi olduğu görüşünde birleşmektedir. Dramatik yazarlık derslerinde çalışmaların detaylı değerlendirilmesi ve tartışma ortamının oluşması açısından bu sayı önemlidir. Yazarlık dersinin yapısı gereği öğrenciyle birebir ilgilenilmelidir. Fazla sayıda öğrenci olduğunda öğretim elemanı gerekli verimi gösterememekte, değerlendirme süresini kısa tutmak zorunda kalmakta, her öğrenciye vakit ayırmada sıkıntı yaşamaktadır. Böylece yapılan çalışmaların istenen nicelikte ve nitelikte olamadığı sonucu ortaya çıkmaktadır. Vurgulanan önemli bir nokta da başvuru sayısının yıllar içinde azaldı̆̆ıdır. Dramatik Yazarlık Eğitimi kontenjanına dair değinilen diğer bir husus ise aday profiline dair yapılan belirlemedir. Başvuran adayların büyük çoğunluğunun sadece üniversiteli olmak adına başvurduğu, sanat eğitimi için ihtiyaç duyulan entelektüel derinlik ve ilgiye sahip olmadıkları belirtilmiştir. Burada lise düzeyinde dramatik yazarlık meslek alanıyla ilgili bilgilendirme ve kariyer yönlendirme eksikliği olduğu sonucu çıkarılabilir.

Dramatik Yazarlık Eğitiminin niteliğinin artırılması için öğrenci kontenjanlarının düzenlenmesinde bölüm görüşlerinin dikkate alınması, kontenjanların on, on iki kişiyle sınırlandırılması önerilebilir. Ayrıca lise düzeyindeki kariyer yönlendirme ve planlama çalışmaları içinde de sanat ve dramatik yazarlık mesleğine ilişkin bilgilendirmelerin yapılması önerilebilir.

4-Programı hazırlama ve izleme stratejileri bağlamında dramatik yazarlık derslerine ilişkin dört yıllık planın tüm anasanat dallarında benzer bir yaklaşımla hazırlanıp sürdürüldüğü görülmüştür. Ders bağlamında kimi farklılıklar olmakla birlikte eğitimde temel ayrılıklar yoktur. Kuruluş ve program stratejilerinin belirlenmesi aşaması tamamlandıktan sonra bölümlerin birbirleriyle akademik paylaşım ve tartışma bakımından iletişim içinde olmadıkları görülmüştür. 
Eğitimin geliştirilmesi, güncellenmesi ve yeni olanakların üretilmesi konusunda Dramatik Yazarlık Eğitimi veren birimlerin akademik ve sanatsal toplantı ile etkinliklerle ortak çalışmalar yaparak deneyim geliştirmeleri önerilebilir. Gösteri sanatlarının yeni olanaklarıyla birlikte Dramatik Yazarlık Eğitimi konusunda da yeni çalışma alanlarının keşfedilmesi ve bunların eğitim kapsamına alınması yine önerilebilecek noktalardan biridir.

5- Kariyer geliştirme destekleri: Dramatik yazarlık öğrencilerine sunulan kariyer geliştirme destekleri öğrenci değişim programları, staj ve pratik çalışma faaliyetleri ve mesleki etkinliklerdir. Yabancı dil yetersizliği yüzünden Erasmus dolaşımının zayıf olduğu görülmektedir. Pratik çalışma ve stajlar Dramatik Yazarlık Eğitiminin aktif, uygulamalı bir eğitim olarak görüldüğünü, sadece metin üretmenin değil, sahne uygulamalarının ve profesyonel gösteri sanatları pratiğinin de öğrencilerin kariyer gelişimlerinde ve yönelimlerinde önemsendiği sonucunu ortaya koymaktadır.

2020 itibariyle hazırlanmaya başlanan üniversite özyeterlikleri ve strateji planları kapsamında kariyer geliştirme ve destek faaliyetlerinin akademik birimlerin temel görevleri arasında görüldüğünü de hatırlayarak, bölümlerin sanat üreten kurumlarla ilişki ve işbirlikleri oluşturmaları önerilebilir.

Araştırmanın genel sonucu olarak, Türkiye'deki dramatik yazarlık anasanat dallarının eğitim programını uygulama konusunda benzerlik göstermekte; mekânsal koşullar, kontenjanlar ve kadro sayıları açısından da aynı sıkıntıları yaşamaktadırlar. Bu başlıkların doğrudan öğrenme performansı ile ilişkisi olduğu düşünüldüğünde sorunların tekrar gözden geçirilmesi, akademik toplantı ya da çalıştaylarla ele alınarak çözüm yolları üretilmesi gerekmektedir. 


\section{Kaynakça}

Arıcı, O. (2020). Kurmacanın inşası: Oyun Yazarlığına Giriş, İstanbul: Habitus Yayıncılık.

Belkıs, Ö. (2020). Tiyatro Yazarlığı, Oyun Yazarlığı- Dramaturgi- Eleştiri, İstanbul: Mitos Boyut Yayınları.

Belkıs, Ö. ve Gümüş, Y. E. (2020). Examining usability of the six thinking hats technique in playwriting education: Turkey as a case study, Pegem Eğitim ve Öğretim Dergisi, 10(1), 147-168.

Belkıs, Ö., Gümüş, Y. E., Şaşmaz, H. ve Alpan, E. D. (2019). Türkiye ve Amerika'da dramatik yazarlık eğitim programlarının karşılaştırmalı olarak incelenmesi, Elektronik Sosyal Bilimler Dergisi, 18(72), 1871-1889.

Belkıs, Ö., Şaşmaz, H., Gümüş, Y. E. ve Alpan, E. D. (2019). Türkiye'de Dramatik yazarlık eğitimi programlarının karşılaştırmalı olarak incelenmesi, Art-E, 12(24), 315-338.

Bıçakçı, H. (2017). Uydurmanın incelikleri, İstanbul: Hep Kitap.

Creswell, J. (2013). Nitel araştırma yöntemleri, beş yaklaşıma göre nitel araştırma ve araştırma deseni. (M. Bütün ve S.B.Demir, Çeviri Ed.). Ankara: Siyasal Kitabevi.

Demirel, Ö. (2015). Eğitimde Program Geliştirme Kuramdan Uygulamaya (24. Baskı b.). Ankara: Pegem Akademi.

Gülsoy, M. (2013). Büyübozumu: yaratıcı yazarlık, 9. Basım, İstanbul: Can Sanat Yayınları.

Miles, M. B. ve Huberman, A. M. (2016). Nitel veri analizi. (S. A. Altun ve A. Ersoy, Çeviri Ed.). Ankara: Pegem Akademi.

Nutku, H. (1999). Oyun yazarlığı düşünsel boyutu ve kavramlarıyla, İstanbul: Mitos Boyut Yayınları.

Nutku, Ö. (1960). Tiyatro ve yazar, Ankara: Gim Yayınları.

Nutku, Ö. (1965). Oyun yazarı, İstanbul: İzlem Yayınları.

Nutku, Ö. (1983). Cumhuriyet Tiyatrosu. Cumhuriyet Dönemi Türkiye Ansiklopedisi. İstanbul: İletişim Yayınları.

Özakman, T. (2001). Oyun ve senaryo yazma tekniği, 2. Basım, Ankara: Bilgi Yayınevi.

Saldaña, J. (2011). Fundamentals of qualitative research. Oxford, New York: Oxford University Press.

Saldaña, J. (2019). Nitel araştırmacılar için kodlama el kitabı. (A. Tüfekçi Akcan, S. N. Şad, Çeviri Ed.). Ankara: Pegem Akademi.

Tiyatro Araştırmaları Dergisi (1978). Tiyatro Öğretimi ve Eğitimi Özel Sayısı, 1976, sayı. 7, Ankara: Ankara Üniversitesi Basımevi.

https://galataperform.com/atolye/oyun-yazarligi-atolyesi-2021/

https://pupasanat.com/V2/dramatik-yazarlik-kursu-bursa

https://kultur.istanbul/tiyatro-yazari-olmak-ister-misiniz/

Çalışmanın etik kurul onayı Dokuz Eylül Üniversitesi'nden (Evrak Tarih ve Sayısı: 21/02/2018, 28924985/216) alınmıştır. 